\title{
From Therapy to Teletherapy: Relocating Mental Health Services Online
}

\author{
FUJIKO ROBLEDO YAMAMOTO, Information Science, University of Colorado Boulder, USA \\ AMY VOIDA, Information Science, University of Colorado Boulder, USA \\ STEPHEN VOIDA, Information Science, University of Colorado Boulder, USA
}

\begin{abstract}
Numerous studies have highlighted a range of potential benefits of teletherapy for clients. Nonetheless, researchers have found that many therapists are reluctant to adopt teletherapy in their work practice. There is a dearth of research about how therapists have appropriated telehealth platforms, either to understand teletherapy practice or to understand the challenges and opportunities for system design. The COVID-19 pandemic offers an unfortunate but unique opportunity to learn more about the experiences of therapists who use a range of therapeutic interventions with a range of client populations. In this work, we explore the following research question: in what ways do telehealth platforms support and challenge the work of teletherapy? We present results of semi-structured interviews conducted with 14 mental health therapists during the first six months of the pandemic in the United States. We present a descriptive account of their experiences as well as a discussion of the ways in which the multi-layered and interdependent nature of two facets of therapeutic work-the therapeutic alliance and the therapeutic interventions-made the transition to computer-supported cooperative work particularly challenging. We then offer a suite of design implications for systems that better support the nuanced and unique work of teletherapy.
\end{abstract}

CCS Concepts: $\bullet$ Human-centered computing $\rightarrow$ Empirical studies in collaborative and social computing; • Applied computing $\rightarrow$ Health informatics.

Additional Key Words and Phrases: Telehealth; teletherapy; online mental health services; COVID-19; remote work

\section{ACM Reference Format:}

Fujiko Robledo Yamamoto, Amy Voida, and Stephen Voida. 2021. From Therapy to Teletherapy: Relocating Mental Health Services Online. Proc. ACM Hum.-Comput. Interact. 5, CSCW2, Article 364 (October 2021), 30 pages. https://doi.org/10.1145/3479508

\section{INTRODUCTION}

Teletherapy-the use of remote technology to specifically conduct synchronous, clinical therapy sessions with clients who are not physically colocated with their mental health therapist-has been shown to provide a variety of benefits for clients, with prior studies reporting that client mental health outcomes using telehealth platforms are similar to those achieved in face-to-face therapy. Researchers have replicated these findings across numerous client populations and using a range of therapeutic interventions. Teletherapy also stands to address a range of physical, emotional, and infrastructural barriers to care $[10,14,15]$.

Authors' addresses: Fujiko Robledo Yamamoto, furo0108@colorado.edu, Information Science, University of Colorado Boulder, UCB 315, Boulder, Colorado, USA, 80309-0315; Amy Voida, amy.voida@colorado.edu, Information Science, University of Colorado Boulder, UCB 315, Boulder, Colorado, USA, 80309-0315; Stephen Voida, svoida@colorado.edu, Information Science, University of Colorado Boulder, UCB 315, Boulder, Colorado, USA, 80309-0315.

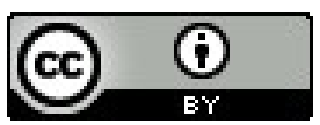

This work is licensed under a Creative Commons Attribution International 4.0 License.

(C) 2021 Copyright held by the owner/author(s).

2573-0142/2021/10-ART364. https://doi.org/10.1145/3479508

Proc. ACM Hum.-Comput. Interact., Vol. 5, No. CSCW2, Article 364. Publication date: October 2021. 
Despite these benefits, researchers have found that many therapists are reluctant to adopt teletherapy in their work practice, citing concerns about the ability to establish a strong therapeutic alliance online, concerns about privacy, and the lack of familiarity with the technology [5, 14, 44, 53] Furthermore, macro-level influences, such as insurance and therapist licensing limitations, have also made the adoption of teletherapy difficult. For example, prior to 2020, in the US, teletherapy was not typically a covered service under most popular health insurance plans [61]. Therapists' licensing boards also did not have clear guidelines for or training on how to deliver teletherapy [15]; as a result, it was not a widespread mode of practice.

While researchers have conducted broad-based survey studies to understand therapists' attitudes towards teletherapy $[5,14,44,53]$, there is a dearth of studies on how therapists practice teletherapy and the extent to which current telehealth platforms actually support the highly nuanced and varied work practices of therapists. As such, we ask:

\section{RQ: In what ways do telehealth platforms support and challenge the work of teletherapy?}

The COVID-19 pandemic offers a unique, though unfortunate, context for learning more about the affordances of telehealth for therapeutic work. The COVID-19 pandemic has resulted in the rapid adoption of and increased use of Computer-Supported Cooperative Work (CSCW) platforms to support all kinds of remote work-including teletherapy. Due to physical distancing protocols and quarantines enacted in response to the pandemic, many crucial frontline services, including mental health services, rapidly transitioned online. In an article from June 2020, the American Psychological Association (APA) reported that 76 percent of therapists were solely providing remote counseling services as a response to the pandemic, which is a stark contrast to the limited number of therapists offering teletherapy prior to this event [7]. With the sudden rise of telehealth and the lack of training and familiarity with the technology, there are concerns that such a rapid switch is leading to an exacerbation of burnout among mental health practitioners [29], particularly at a time when mental health services are increasingly crucial. Mental Health America reported an increase in clinical anxiety since February 2020 [3] and Brooks et al. [13] published a rapid review that summarized the negative psychological effects of the quarantine, including increased post-traumatic stress symptoms, anxiety, depression, and exacerbation of current psychological disorders. Experts expect these negative effects to continue beyond the duration of physical distancing protocols. There is and will be a high need for mental health services through this crisis and beyond, and teletherapy makes it possible for many of these needs to be met. Despite some of the reticence surrounding the adoption of teletherapy, many researchers predict that the pandemic has accelerated the acceptance of teletherapy as a legitimate way to provide mental health services $[78,80]$. If teletherapy is, indeed, here to stay; it is all the more urgent that we develop better platforms to ensure that therapists are comfortable and confident in carrying out their work in an online setting.

While there is vast literature concerning remote work (e.g., [30, 38, 62]) and telemedicine $[8,23]$, teletherapy is significantly different from these other types of online interactions. Therapy consists of a unique relationship between client and therapist; it requires the establishing of a safe place where clients can discuss sensitive concerns and take calculated risks in order to ameliorate mental health concerns (i.e., such as trying out new skills, talking about a traumatic event, learning breathing techniques, etc.). The implicit social contract between therapist and client is different from other social contracts surrounding business meetings, educational environments, doctor-patient interactions, and other types of collaborations that may occur online. Because of this, telehealth platforms have to support the unique work of therapists in creating a safe and healing space for the client, a fundamentally different design constraint and proposition than has driven other CSCW technologies. As such, there is a critical need to examine how these existing technologies have been 
appropriated across a range of teletherapy practices and to understand system requirements that might be more specific to creating effective telehealth platforms for therapists. In this research, we document the uniquely high-stakes experiences of mental health therapists, as they relocate their entire caseloads online, in order to inform the work of HCI designers and CSCW researchers [17]

In what follows, we first offer a summary of related research on teletherapy. We also provide a high-level overview of the work practices of therapists as context for the results that follow. We then describe our semi-structured interview study-one of the first descriptive empirical accountsof the experiences of 14 mental health therapists in using telehealth platforms, especially those who would not have normally chosen to conduct remote sessions with their entire caseload. We characterize the incredible effort that these therapists undertook in order to relocate their work, from challenges with the adoption and use of telehealth platforms for therapy to their creative appropriation of these technologies. We disentangle different facets of therapeutic work to discuss how the multi-layeredness of relocating this work poses unique opportunities and challenges to computer-supported collaborative work. Finally, we present four opportunities for improving the design of telehealth platforms to better meet the unique needs of mental health therapists and suggest ways in which these can also be extended to other types of remote work.

\section{RELATED WORK}

Several systematic and critical reviews argue that teletherapy can result in client outcomes that are comparable to the outcomes from face-to-face counseling sessions $[9,20,32,71]$. Research also highlights a range of potential benefits of teletherapy, including addressing barriers to care, such as lack of transportation, feelings of shame for seeking counseling, constraints associated with certain disabilities, and creating more opportunities for access to mental health for rural and underserved communities $[10,14,15]$. This body of research suggests that teletherapy can benefit a variety of client populations, as well, including individuals who have anxiety disorders $[12,14,60]$, mood disorders [9, 14, 63, 72], trauma-related disorders [1, 46, 79], and anorexia [4]. Researchers have also conducted empirical studies to evaluate the success of teletherapy in supporting specific therapeutic interventions with specific client populations, such as interventions to improve parentchild relationships [27, 32], solution-focused interventions for college students [24, 60], and artbased interventions for veterans who live in rural areas [46]. The benchmark for much teletherapy research, then, is to assess whether the use of teletherapy can result in similar client outcomes as face-to-face therapy sessions, which are considered the gold standard for the treatment of mental health [81]. While the perspectives and outcomes of the client are crucial for the adoption of teletherapy, it is also important to understand the challenges that therapists face when adopting telehealth platforms into their practice.

Nearly all of the studies that have focused on the perspectives of therapists have consisted of adoption and attitudinal surveys. Most of these have found limited use of teletherapy among clinicians $[5,14,44,53]$. While therapists with previous experience with telehealth platforms tended to hold more positive attitudes about its effectiveness [14, 53, 76], most of the clinicians reported concerns about teletherapy due to perceived difficulties in establishing a therapeutic alliance online [14,53], the accessibility of telehealth software [5, 53], and privacy concerns [5].

Researchers have highlighted the importance of identifying and understanding the technology needs of the different stakeholders using telehealth systems to develop more usable and beneficial systems $[51,68,77]$. And yet, there is a dearth of studies of teletherapy practice and of therapists' experiences with teletherapy. One notable exception is Mitchell's thematic analysis of the perspectives of six integrative psychotherapists in the UK who use telehealth technologies [57]. Her findings reveal that despite the absence of physical contact, the psychotherapists she interviewed are still able to engage in deep relational work and are able to develop a strong therapeutic alliance with 
their clients. Mitchell does note that her sample self-selected based on their interest in teletherapy and that "if a more random sample was sought, then more extreme findings against online use may have been apparent" [57, p. 133]. More research like this is needed, then, to understand the experiences of a broader diversity of therapists including those who work with a range of client types and ages, use a variety of therapeutic modalities, and have differing levels of experience with teletherapy.

Researchers have also noted other, macro-level barriers, including limited access to telehealth platforms by communities with limited or no internet connectivity and a lack of comfort with using technological tools [55], licensing regulations [19], and insurance limitations [61]. There are also organizational characteristics (i.e., nonprofit versus private practice) that could influence the adoption of teletherapy [41, 70, 84]. Interestingly, some of the macro-level influences that are framed as barriers in some research are framed as benefits in other research. For example, some researchers posit that teletherapy can increase the availability of mental health services for individuals in rural areas [46], while other researchers posit that that lack of broadband access in rural areas might, instead, be a barrier to access, especially for those with a diagnosis of serious mental health conditions [43]. More research is needed to understand how these various influences actually play out.

\section{METHODS}

\subsection{Research context: The work of therapists}

We present background information on the foundational properties of therapeutic work. This is not meant to be exhaustive of all of the work that therapists do, but rather, it is a synopsis to help the reader better contextualize the accounts of the therapists that we interviewed.

While the stereotypical image of therapy consists of a therapist listening to a client, therapeutic work can take on different forms. Therapists may play board games with their clients, play music, create art together, or simply sit and talk [67]. Therapists often work with clients for between 30 minutes and one hour [67], and they typically adapt their physical space to better engage their clients [31]. For example, therapists may have toys or art supplies on hand. There may be specific sections of the room that are more kid-friendly, and others that are designed to meet the needs and interests of adolescents. The duration of the session and the style of the room is dependent on the client's developmental level, attention span, and agency or insurance expectations.

Therapists can engage in either directive or non-directive therapy [35]. Non-directive approaches follow a person-centered philosophy-the client takes the lead in what they want to discuss and what they want to work on. From this perspective, the client is the expert and the therapist creates a safe space for the client to explore their thoughts and feelings. Directive approaches, on the other hand, focus on the therapist providing a specific intervention and direction for a session. Most therapists utilize a combination of these approaches depending on what seems the most appropriate for the client with whom they are working.

Duncan, Miller, and Sparks [22] argue that client mental health outcomes are most dependent on the client themselves and on extratherapeutic factors such as social support and the client's environment. After that, client outcomes are most significantly affected by the therapeutic alliance [2, 22, 50], which is the collaborative relationship established between a client and a therapist [11]. There are several therapist-related attributes that contribute to the development of a strong therapeutic alliance: therapist communication skills, perceived trustworthiness, confidence, warmth, and empathy [2]. Therapists assess the therapeutic alliance both by verbal feedback from clients and by assessing a client's nonverbal cues [33]. Nonverbal communication includes gestures, eye movements, facial expressions, body movements, and posture [26]. These cues offer therapists important 
information on how the client is reacting to the session content, whether they are engaged or distracted, and how well they are regulating their emotions [69]. The therapeutic alliance is limited by the therapist's professional code of conduct, which indicates that therapists must not engage in dual relationships with their clients [6]. Even though the relationship between therapists and clients is intimate due to the nature of the work that is done, there are still strict boundaries which differentiate the therapeutic relationship from other close, personal relationships.

The ways in which the unique work practices of therapists are relocated online, via teletherapy platforms, is an open empirical question, and one that we take up in this research.

\subsection{Positionality Statement}

The first author of this paper worked as a clinical therapist for 7 years. She worked primarily with Spanish-speaking families who had experienced trauma due to child abuse. Her previous experience as a therapist provided particular insight in understanding and contextualizing the experiences of therapists who are transitioning to teletherapy.

\subsection{Participants}

We recruited 14 mental health therapists through our existing professional networks and professional groups on social media. Three participants were recruited through the researchers' personal networks; the remainder of the sample did not have a previous relationship with the research team. The gender breakdown of our sample is as follows: 11 females, 1 male, and 1 non-binary; the predominance of females in our sample matches a gendered skew in the profession [48]. We interviewed therapists from different regions of the US, including 4 from the West South Central region, 3 from the East North Central region, 5 from the Mountain region, and 2 from the South Atlantic region. Of the therapists we interviewed, 3 work exclusively with clients from rural areas, 6 work with a mixture of clients from rural and urban areas, and 5 work with clients from rural areas occasionally. Half of the participants worked at community mental health organizations while the other half worked in private practice. The gender, region, work site, and client demographic of the therapists was omitted from the demographics table to protect their identities (Table 1).

We interviewed therapists with a range of professional experience providing mental health services (i.e., 1 year to 30 years) and different client types (i.e., some work with specific mental health concerns such anxiety, depression, trauma; certain client populations such as immigrants, trans, chronic illness; some specialize in working with different age groups, etc.). We sampled diversely to learn about how the platforms supported the work of different styles of therapy for different types of clients. Nine of the therapists interviewed had never provided teletherapy services prior to the pandemic. Four therapists had provided teletherapy services previously, but only in rare situations (i.e., clients were unable to attend in-person sessions due to weather or health concerns). These participants responded to our call for participation because despite having previous experience with teletherapy, they still faced difficulties with transitioning their entire caseload online. Only one of the therapists we interviewed exclusively provided teletherapy services for the last 10 years. This participant responded to our call for participation because despite his experience with teletherapy, there were still sociotechnical concerns that he wished to share to help improve the design of telehealth platforms.

\subsection{Data collection}

We conducted semi-structured interviews $[16,75]$ to better understand how therapists are selecting platforms, the advantages and challenges of doing teletherapy, and how therapists are leveraging resources available to adapt therapeutic techniques online. We offered participants the choice to either complete an interview on Zoom or via an application where they could complete the 
Table 1. Summary of Participant Demographics

\begin{tabular}{|c|c|c|c|c|c|}
\hline $\mathbf{P} \#$ & $\begin{array}{l}\text { Years of } \\
\text { professional } \\
\text { experience }\end{array}$ & Area of specialization & Client Types & $\begin{array}{l}\text { Telehealth } \\
\text { used since }\end{array}$ & $\begin{array}{l}\text { Telehealth } \\
\text { platforms used }\end{array}$ \\
\hline P01 & 5 years & Trauma therapy & All ages & March 2020 & $\begin{array}{l}\text { Doxy.me } \\
\text { Zoom }\end{array}$ \\
\hline P02 & 30 years & Expressive therapy, trauma therapy & All ages & March 2020 & $\begin{array}{l}\text { Doxy.me } \\
\text { Phone (audio-only) } \\
\text { Zoom }\end{array}$ \\
\hline P03 & 1.5 years & General mental health concerns & All ages & March 2020 & $\begin{array}{l}\text { Zoom } \\
\text { Facetime } \\
\text { Google Duo }\end{array}$ \\
\hline P04 & 9 years & Trauma therapy & All ages & March 2020 & $\begin{array}{l}\text { Doxy.me } \\
\text { Zoom }\end{array}$ \\
\hline P05 & 1 year & General mental health concerns & All ages & March 2020 & $\begin{array}{l}\text { Google Meet } \\
\text { Phone (audio-only) }\end{array}$ \\
\hline P06 & 1 year & General mental health concerns & All ages & March 2020 & Google Hangouts \\
\hline P07 & 20 years & $\begin{array}{l}\text { Cognitive behavioral therapy (CBT), } \\
\text { brainspotting }\end{array}$ & All ages & March 2020 & $\begin{array}{l}\text { Google Meet } \\
\text { Zoom } \\
\text { Phone (audio-only) }\end{array}$ \\
\hline P08 & 5 years & $\begin{array}{l}\text { Marriage counseling, } \\
\text { general mental health concerns }\end{array}$ & $18+$ & March 2020 & $\begin{array}{l}\text { Google Voice } \\
\text { Google Meet }\end{array}$ \\
\hline P09 & 26 years & $\begin{array}{l}\text { Anxiety, post-traumatic stress } \\
\text { disorder (PTSD), depression, dual } \\
\text { diagnosis, obsessive-compulsive } \\
\text { disorder (OCD), thought disorders }\end{array}$ & $25+$ & $\begin{array}{l}10 \text { years (only } \\
\text { offers telehealth } \\
\text { sessions) }\end{array}$ & $\begin{array}{l}\text { Google Meet } \\
\text { Zoom }\end{array}$ \\
\hline P10 & 5 years & $\begin{array}{l}\text { Anxiety, chronic illness, LGBTQ, } \\
\text { eye movement desensitization } \\
\text { and reprocessing (EDMR) }\end{array}$ & $11+$ & $\begin{array}{l}\text { Jan } 2020 \\
\text { (as an option } \\
\text { for clients) }\end{array}$ & Google Meet \\
\hline P11 & 12 years & Expressive therapy, trauma therapy & $17+$ & $\begin{array}{l}\text { Jan } 2019 \\
\text { (as an option } \\
\text { for clients) }\end{array}$ & $\begin{array}{l}\text { Zoom } \\
\text { SimplePractice } \\
\text { Sondermind }\end{array}$ \\
\hline P12 & 5 years & Black, Latino, trans & $18-44$ & $\begin{array}{l}3 \text { years } \\
\text { (as an option } \\
\text { for clients) }\end{array}$ & $\begin{array}{l}\text { Google Voice } \\
\text { (audio only) } \\
\text { SimplePractice }\end{array}$ \\
\hline P13 & 8 years & $\begin{array}{l}\text { Immigrants, queer, depression, } \\
\text { anxiety, life transitions }\end{array}$ & Young adults & $\begin{array}{l}\text { Always an } \\
\text { option for } \\
\text { clients }\end{array}$ & $\begin{array}{l}\text { Zoom } \\
\text { Phone (audio-only) } \\
\text { Doxy.me }\end{array}$ \\
\hline P14 & 8 years & $\begin{array}{l}\text { Child protective services (CPS)- } \\
\text { mandated clients }\end{array}$ & All ages & June 2020 & $\begin{array}{l}\text { Google Meet } \\
\text { Doxy.me }\end{array}$ \\
\hline
\end{tabular}

interview asynchronously. We offered this asynchronous option to accommodate different constraints that participants may be experiencing due to the COVID-19 pandemic. All but one of the participants opted to participate in an interview via Zoom (with an average length of 56 minutes). The other participant chose to answer the questions via email (i.e., the first author would email a question/follow-up questions, and the participant responded at their convenience). Researchers have found that email exchanges can be a helpful tool for interviews and that it can lead to rich and thoughtful narratives $[40,54]$.

Our semi-structured interview consisted of questions to better understand:

- Changes in service provision (i.e., what technologies are being used? How are they being used and for what types of services? How has the work changed since the declaration of the public health emergency?) 
- Platform selection process (i.e., what platform did you consider? How did you select the one you use? How was the onboarding process?)

- Experiences with teletherapy platforms (i.e., asking participants to walk us through how they use the platform in sessions and asking questions related to what's working, what could be different, and how clients are adapting to the sessions)

- Therapist support and resources (i.e., what resources are available? How are they briefing cases? What technologies are being used to facilitate therapist support?)

We also asked demographic questions related to how long participants have been practicing as mental health providers, the types of clients they work with, the areas they specialize in, and the platform(s) they currently use to conduct teletherapy. We adapted specific questions for each interview, based on our evolving understanding of how clinicians are adapting to remote mental health sessions. If the participants had stated that they had used teletherapy prior to the pandemic, we asked them similar questions related to how they selected platforms, what factors contributed to them deciding to pursue teletherapy, whether or not things had changed due to the pandemic, and their overall impressions of teletherapy. We continued collecting data until we reached theoretical saturation across the breadth of experiences shared by the diversity of informants that we recruited. Here, our goal was not to capture the experiences of one type of therapist or the experiences of adapting one therapeutic intervention. Instead, we focused on obtaining a general understanding of the cross-cutting experiences of therapists from different backgrounds and levels of experience in adapting their entire practice to a telehealth platform. In this case, theoretical saturation was reached when the participants expressed similar expressions of the challenges related to translating their form of therapy to teletherapy and in establishing a safe space, similar expressions of the benefits and trade-offs of being 'in' the client's space during their sessions, similar expressions of the difficulties related to the lack of relational cues and the technical limitations of teletherapy, and similar expressions of challenges related to the personal burnout and lack of access to one's own support network.

Regardless of participants' prior experience with teletherapy, each participant shared similar experiences, with the exception of the one participant who had the longest experience with teletherapy. He reported similar challenges to adapting his therapeutic interventions to teletherapy, the difficulty in interpreting relational cues online, and provided details of the technical challenges he and his clients often experience. The key difference between this participant and the others related to the personal burnout experienced. This participant indicated low levels of exhaustion and burnout, particularly because teletherapy fit his particular lifestyle. He also had more time to adapt to this way of doing therapy.

\subsection{Recruitment timeline in relation to COVID-19 pandemic}

Due to the COVID-19 Public Health Emergency declared in the United States, the federal government, some state governments, and insurance carriers relaxed restrictions surrounding the use of telehealth to provide mental health services. Beginning in late March 2020, the Office for Civil Rights at the Department of Health and Human Services allowed for mental health practitioners to use platforms that are not HIPAA compliant (i.e., FaceTime, Zoom, Google Hangouts, etc.) [61]. During the pandemic, therapists were allowed to bill insurance providers as if they were providing in-person sessions and to practice teletherapy across state lines, which is typically not allowed by most states.

We began recruitment in the early months of the COVID-19 pandemic (Figure 1). Most of our informants were interviewed during the early months of the pandemic-the majority had littleto-no experience providing teletherapy services. Also, many of them had to transition to offering 


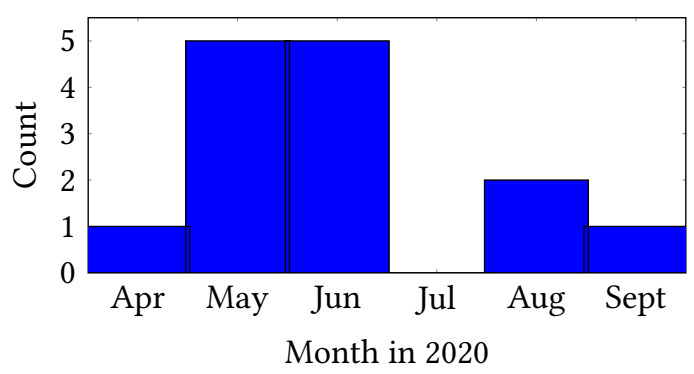

Fig. 1. Number of Interviews by Month in 2020 Pandemic

teletherapy sessions to their entire caseload within a week. We were able to capture many of the early experiences of how therapists adapted to teletherapy, some of the barriers they were facing, and the creative solutions they were implementing to try to provide the best care they could. We took a brief break from interviewing during the month of July and recruited additional therapists in August and September to better understand whether the perspectives and/or experiences of therapists who had used telehealth platforms for longer durations, as the pandemic wore on, might differ from the informants who we interviewed more shortly after the emergency shift to teletherapy.

\subsection{Data analysis}

We transcribed audio from the interviews and conducted iterative and inductive analysis of the transcripts using open coding and thematic analysis [16]. The first author wrote memos after each interview and started creating open codes after seven interviews to better target future sampling. Initial codes included examples such as "engagement on telehealth platforms seems challenging" and "therapists are exhausted." The first author conducted walkthroughs of each interview with the rest of the research team during weekly meetings. The walkthroughs highlighted initial codes, and discussion centered around similarities and differences among participant experiences as well as higher-level themes. One outcome of the interview walkthroughs was consensus around what cross-cutting themes should be explored further through memoing. In addition, the research team used MURAL ${ }^{1}$ to document open codes and engage in collaborative thematic analysis during virtual team meetings (Figure 2).

All of the authors iterated through a second round of open coding following the completion of all interviews to ensure that each of the coding categories captured the breadth of experiences of the therapists that we interviewed. Some open codes were combined as we iterated through analysis (e.g., codes related to the difficulties of conducting trauma therapy versus differences in expressive therapies were combined into "certain therapeutic interventions needed to be reconfigured"), but most transitioned directly into the subsections of the results reported below. We then turned to exploring the relationships between these coding categories through memos about cross-cutting themes, such as "adapting to teletherapy over time," "the creative appropriation of telehealth technologies," "the blurring of boundaries and information overload," and "the future of mental health services." Across these memos, two interdependent facets of therapeutic work-the therapeutic alliance and the therapeutic intervention-came to the fore as having distinct opportunities, challenges, and costs for teletherapy practice. We disentangle the work of relocating both facets of therapeutic work in the discussion.

$\overline{{ }^{1} \text { https://www.mural.co }}$ 


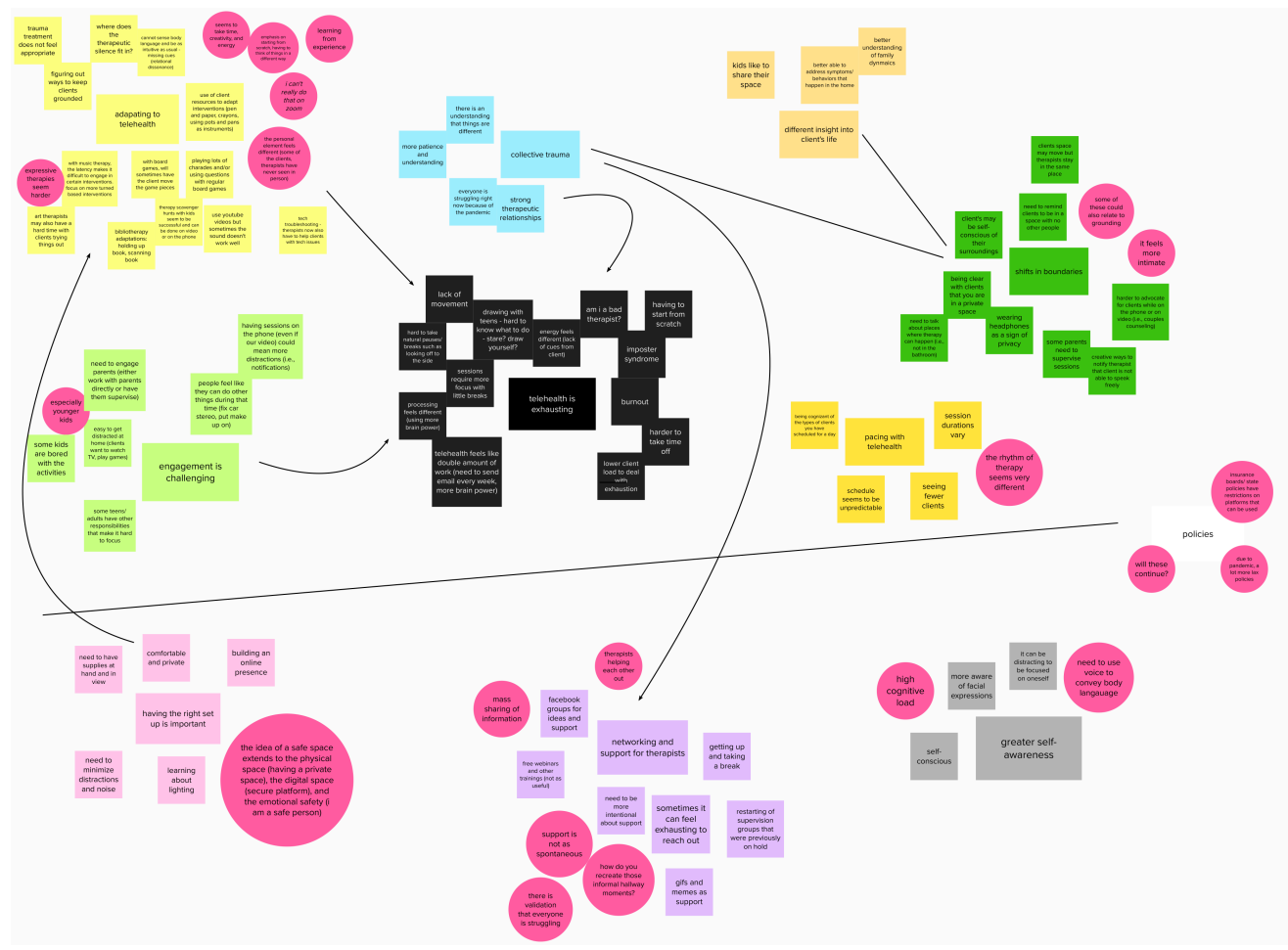

Fig. 2. The MURAL board in which the research team discussed open codes.

We performed member checking [18] by sharing a summary of the results with all of our participants. We asked participants to review the findings to ensure that they were representative of their experiences and that we did not leave out any topic that was especially important to discuss. Six of the participants responded and affirmed our conclusions. For example, one participant stated "This feels like a strongly accurate snapshot of what we encounter as telehealth therapists" and another one said "Thanks for sending your results, I must say I agree with them. I don't have anything to add." No participants responded with any concerns or corrections.

\section{FINDINGS}

\subsection{Therapists use a range of popular platforms for teletherapy sessions}

All of the therapists we interviewed used a combination of platforms, which are represented here (see also Table 1). The most popular platforms used by therapists included Zoom $(n=8)$, Google Meet $(n=6)$, and doxy.me $(n=4)$. Less commonly, therapists reported using audio-only phone sessions $(n=4)$ or Google Voice $(n=2)$, FaceTime $(n=1)$, Google Duo $(n=1)$, Google Hangouts $(n=1)$, Simple Practice $(n=2)$, and the Sondermind ${ }^{2}(n=1)$. The choice of what platform to use depended on the agency they work for; client preference; reliability, cost, and ease of use of the platform; and state and federal policies.

Many therapists talked about how the different platforms can be unreliable at times, especially if a client does not have a strong internet connection. If there are connection issues, P01 explained

\footnotetext{
${ }^{2}$ Both Sondermind and Simple Practice are therapy practice management software that integrate telehealth, online booking, paperless intakes, and more.
} 
that they try to troubleshoot as best as they can: "So I ended up calling him on his cell phone, so the audio was through the cell phone, but we were still doing the video portion through the Zoom, so that worked with him."

Sometimes, therapists have to switch to a different platform, as stated by P04, who typically uses Doxy.me:

I will say, there have been a couple times when it's been way too glitchy. It'll catch. And so the person freezes and sometimes we do have a Zoom account. And so I will just tell them, 'Hey, let me just send you a Zoom invite' because it works better than this. (P04)

There are also certain platforms that are better for group therapy. For example, Doxy.me does not allow for large groups for group therapy:

Doxy only allows 10 people on group at [a] time, which also includes a facilitator. So like in my teen group, if everybody comes, there is, I think there's 12 girls, so I would have to split the group and that sort of changes the dynamic of the group if they are not all together. (P01)

Most therapists indicated that they preferred Zoom for group therapy, especially since it allows control over who is featured, has screen sharing capabilities, and has a waiting room.

Therapists also have to provide technical support to clients to make sure that they are able to join in the session.

I look for a confirmation from them that they plan on attending the appointment, then if it's a few minutes into the appointment and they haven't joined yet, I'm telephoning them to ask if there are connection problems. So I'd say maybe 20 percent of people need a little assistance from me. (P09)

This technical support consists of things such as re-sending the links to the platform, helping the client install any software or applications that are needed, troubleshooting connectivity issues, and/or transitioning to a different platform if needed. While many therapists talked about liking Zoom, they did not like that clients have to download the software/application in order for it to work. With other platforms, the client is simply able to join by clicking on a link.

Therapists also talked about preferring platforms that easily link to other technologies that they use (i.e., email accounts, calendar, note-taking software). Most of the platforms however, did not support this. Therapists mentioned feeling like they have to do "double the work" because of this:

There was like double paperwork and it's double work. So, you know, the day before session, I send an email out or an email reminder cause half the time you don't even know what day it is anymore. Right now, you know, here's a reminder of our session tomorrow at two o'clock and here's the link. You know, even though the link never changes but I just send that link so it's fresh and in front of them. But then I have to go and put a note in that I did a client communication. So it's like, I feel like I'm double noting everything. (P01)

When it is available and possible, all the therapists interviewed preferred video sessions over audio-only phone calls. P05 stated that "video chat gives you more of an option to do activities 'cause you can do fun things" but indicated that she tries to be flexible and "tailor the type of session to the extent to which the client is willing and able to create that space." Some clients are reluctant to do video sessions, either due to lack of comfort with being on video or lack of technology literacy, and therefore opt for audio-only calls. This was especially true for the therapists we interviewed who work in rural settings or those who work with low-income clients. P05, for example, wonders if many of her clients choose phone sessions because "they feel self conscious about their surroundings, too, 'cause I see mostly very low income clients, you know, and they might think that I care. I don't, but you know, but they might just feel a little self conscious about their surroundings." 
P12, who works with the trans community, indicated that the option not to have video calls was actually empowering and safe for her clients: "So for those clients not being on video and not being in person, it's sometimes actually better for them 'cause they're not thinking about their appearance or your thoughts about their appearance. So it's been pretty useful for those groups."

While therapists focused on choosing platforms that were the most comfortable for clients, they were also constrained by agency, state, and federal policies. The COVID-19 pandemic led to changes in state and federal regulations regarding telehealth, particularly the ability to use non-HIPAA-compliant platforms during the early months of the pandemic. Most of the therapists who work at nonprofit agencies used non-HIPAA-compliant platforms because they were the most affordable and most agencies did not have funds to spend on telehealth platforms. The majority of therapists did not have much autonomy over what platform they used; these decisions were made at the organizational level.

\subsection{The sudden transition to teletherapy was challenging}

While some of the therapists we interviewed had previous experience with teletherapy, all but one of the therapists reported difficulties and challenges in transitioning their entire caseload due to the 2020 pandemic. These difficulties were present for the therapists we interviewed in the early stages of the pandemic and for those who we interviewed four months into it. These challenges emerged from using the technology itself, having to adapt their interventions, and suddenly being displaced from their work setting and co-workers, who serve as a source of support throughout the day.

Five out of the 14 therapists we interviewed had prior experience with teletherapy. While these therapists were familiar with some aspects of teletherapy, they discussed the difficulty of moving their entire caseload online and still not feeling comfortable with teletherapy. P11, for example, commented that "I still feel like I still would rather see people in person." Others reflected that not having any in-person sessions was particularly challenging:

For the ones who've always done a mixture of in person and some telehealth... they've always noticed either that they feel a little disconnected because they're not seeing me in person so my feedback may come off a little more callous when they can't like, see me physically. (P12, has offered telehealth since 2018)

For the 9 therapists who had not done teletherapy before, the transition was also quite challenging. One participant described it as "traumatic" for both herself and her clients:

And that's been a little bit challenging because I have some clients that, I don't know, have never used computers before. So at the very beginning, I was seeing a lot of ears, you know, people talking through their phones that way. It was a very sterile feeling. And so to have, you know, a lot of the times when you have really, really big things happen, you at least get to come into your therapist's office and sit on a couch or talk about it. So, like dad's dying or I was in a car accident and broke my leg, and, you know, things like that. You get to come in and you get to sit on the couch and so to have a pandemic come up and then have to see your therapist in a little box that's grainy and it freezes-I feel like that was pretty traumatizing, itself. (P08)

Some therapists also talked about how it is easier for them to replicate certain aspects of therapy with clients who are familiar with the style of therapy. These clients already knew what to expect from therapy-they simply had to become familiar with the technology.

The difference with that group is that everyone remembers what it was like in the building and so they kind of know why we're doing it. And so I think there's like some kind of transfer there. I think if it was the first time doing it and we were all in a group, I think that actually might be kind of difficult. (P02) 
Many therapists reported that their client load initially dropped, especially during the early months of the pandemic. Some therapists indicated that their clients did not feel comfortable conducting sessions online. This led to therapists taking on new clients, most of which they had never met in person. For example, P08 described it as a "weird" experience: "I have a significant portion of my clients I've never actually met in person, which is very weird to me because I never signed up for that." Despite this "weirdness," therapists are working with clients in ways they believe are making the sessions productive and meaningful for clients.

\subsection{Recreating the therapy room (a safe space) online through collaboration}

Therapists, especially those who work with children, had to work towards recreating the therapy room online. There is a lot of work that goes into designing therapy rooms: selecting the proper ambience (i.e., lighting, room configuration) and selecting the type of materials (i.e., drawing supplies, toys, books, etc.) that are appropriate for the types of clients with whom a therapist works. For example, a therapy room may have a sandtray with figurines, puppets, art supplies, a table or a couch, musical instruments, board games, books, etc. Not all therapy rooms will contain the same items and some may be simpler, especially if the therapist works with adults only. The variations also depend on the therapist's clientele, agency or therapist resources, and the types of interventions the therapist employs. The therapy room is designed to help clients feel comfortable and engaged. Through teletherapy, therapists have had to collaborate with clients (and their caregivers, in some cases) in order to recreate the therapy room.

I asked the parents or the guardians a lot to have some crayons and some paper 'cause sometimes the kids are just drawing different pictures. I do a lot of bibliotherapy with them, so I'm reading books and some of the books I have had a chance to scan so I can do a share screen instead of just taking the book up and holding it. (P01)

As mentioned by P01, there is also additional work that needs to happen in order to set up the therapy room. This ranges from selecting and learning how to use a specific platform, learning the different functions of each platform (i.e., screen sharing, security settings), and creating digital content for clients (i.e., creating digital copies of books, worksheets, etc.). Therapists are also depending on clients having supplies at home that can be used for therapy, as exemplified below:

She used her Candy Land game and moved the pieces for both of us. And then I had the, the plan of, you know, if you land on a yellow, talk about something happy. If you land on, you know, green, something. You know, so I was able to do that. And I haven't seen her for several months and through that, she actually started opening up about abuse, her abuse, which was pretty cool. (P01)

Typically, we would be in the gym with him, maybe shooting hoops and you know, being therapeutic through that. So, we can't do that. So in his room, he had a trash can and he had paper. So we had to make a basketball with this paper. And so you're shooting, he's moving, shooting, and you're doing therapy. So you just kind of adapt to whatever they have at that time. (P04)

Therapists indicated that they spent a lot of time and energy into setting up their spaces. One participant described this process as "learning from experience" (P07). This process involved rethinking the therapeutic spaces and trying to ascertain which features can be translated online. P01 described how she set up her space to resemble her therapy room: "so I have my little bookshelf, so I've got my little space now and I can actually turn my computer here. So I've got everything within reach that I can grab. I can grab my puppets, I can grab you know, books and I've got a white board."

Part of creating a therapeutic space also involves the therapist themselves working towards "marketing themselves as safe" (P12). Most therapists typically do a consultation with a client prior 
to starting therapy to ensure that the therapist and client are a good fit. This is harder to do when clients are not able to meet the therapist in person. Some therapists are using their web presence as a way for clients to develop a better understanding of who they are as professionals.

A lot of my clients have told me that they've looked at my website. So they've gone beyond my private practice listing and see my website and like what they see there. I have some blog posts up and descriptions about me and my practice that match my therapy style. And if they stalked me even further and found anything on YouTube that I've done in terms of like talks or panels, just trying to get as much of a sense of who I am and how I talk, like as they're researching me online so that when we're in this $2 D$ interface it's not as like feeling as a lack of relationship because they've already met me digitally. (P13)

Furthermore, this re-creation of the therapy space also involves a partnership with the client in thinking about ways to create a safe space from their end. Therapists are encouraging clients to find a quiet space (to the extent possible) so that clients minimize distractions and feel comfortable sharing. Rituals are also an important part of the therapeutic process, so therapists are trying to help clients as much as possible in bringing in aspects of the therapy room into their own house. P11 describes this as follows: "I think the consistency of coming to the same place creates a consistent and safe container." P13 talks about how a client's stuffed giraffe helps create that consistency, even if the client may be moving around in their space.

I offer for them or encourage them to use parts of their own physical space to keep them centered during our sessions. So, like for example, I had a client who had a stuffed giraffe that they really enjoyed and that they would bring in to physical sessions and then when transitioning to telehealth, they would just still keep the ritual of bringing that with them online or like bringing in their cat or dog or whatever. (P13)

Therapists are focusing on helping clients feel safe, whether it is by encouraging them to find safe and quiet spaces in their homes or by therapists themselves working towards "marketing" themselves as safe.

\subsection{Certain therapeutic interventions need to be reconfigured for teletherapy}

10 of the therapists we interviewed stated that expressive art therapies, such as art, music, and play therapies, are difficult to do in telehealth platforms. In particular, most child therapists had to spend time researching and reconfiguring activities for teletherapy. P03 stated that she had to "start from scratch when we moved to telehealth 'cause there wasn't a way to do that effectively." Multiple participants mentioned belonging to a Facebook group for therapists that increased from a couple hundred members to about 20,000 members as therapists were scrambling to help each other to develop interventions that could be done on video or through audio-only channels (P01, P02, P03, P04, P05, P07, P11, P12).

Therapists who rely on music-based or art-based interventions faced significant difficulties. P02 explained that many music therapy interventions involve both the client and therapist playing music at the same time to support emotional regulation. On both Doxy.me and Zoom, it is difficult to achieve this since there are lags in the connection: "It's difficult for the back and forth in music therapy because there's some latency with playing together" ( $\mathrm{P} 02)$.

Another expressive arts therapist (P11) stated that it is difficult to encourage clients to try art therapy techniques online.

As an art therapist, it's tricky because clients that came to me to do art therapy, they'll probably still do art in some way during the session, even if it's like for a little bit. They're already set with artmaking when we get together. So, I think it still feels very different to me. I never of course would force anyone to do anything, but I feel like it's harder to 
encourage people who might try it. It's harder to do that online. They're like, "Yeah, no, no thanks, hard pass." (P11)

Trying things such as art and music online seems to be much harder than trying these activities in a therapy room. P11 explained that there is something "powerful" about taking risks in a therapy room, and that it is harder to do this on video platforms.

Those who run therapeutic groups are also facing challenges in delivering their interventions. P01, who runs a group for teenage girls, talked about how she uses the features of the platform to manage the group: "We've got everything locked down, so no recording, no side chats, anything like that, because we know the teens would start doing the side thing."

P01 also talked about having to establish different rules for running a teen group online. For example, she had her group come up with a safe word so that the group could stop discussing sensitive topics in case someone (i.e., a family member, a friend) walked into the room during the group session.

There are also some clients who are facing difficulties finding a safe space within their home. Many of the therapists we interviewed talked about how they do not feel like it is appropriate to work through traumatic memories if they are not in person with the client. For example, P05 talks about a new client who has experienced a traumatic event but is not able to work on it with his therapist because he is typically supervising children during their therapeutic session:

I've got a client who needs to talk about a traumatic experience. He's one of mine who actually started by phone-like, we've had all our sessions by phone. I don't know what the guy looks like. But anyway, but he just, and I agree that it's not appropriate to try to talk through his traumatic experience just because it's not a controlled environment. He's actually supervising children. (P05)

Trauma therapy typically involves working through a traumatic memory while a therapist helps the client create a safe space where they feel grounded enough to regulate their emotional response to their traumatic memories. Therapists check in both verbally and nonverbally to make sure the client is regulating their emotions so that they are not retraumatized by their memories. P08 indicated that she did not feel comfortable talking through a client's trauma in a client's space because it can be "traumatizing when they're still in a physical place where they've been traumatized."

Despite these difficulties, therapists are adapting in various ways. For example, some are using more turn-taking interventions (i.e., playing a board game) or using client resources, such as material around their home:

We do a lot of board games while we talk in regular sessions. So, stuff like that. We were doing-someone sent around some therapy Mad Libs. I did a couple of those with my eight-year-old clients. I've been doing get-to-know-you questions through a few games or things like that over the phone with some clients. (P05)

Most of my clients don't have any instruments at home, so we're using like pots and pans or pencils. (P02)

Therapists and clients are also being flexible and more intentional about how the session time is used. Therapists stated that their session time has changed since transitioning to teletherapy, with many sessions being much shorter than usual. P05 described how her sessions with children are now about 30 minutes compared to 45 minutes, and that her sessions with adults have decreased from 60 minutes to $45-50$ minutes.

Some of our sessions now are more just kind of like touching base, checking in, you know, dealing with kind of just providing a little bit of social support for some of the stress our clients are going through right now. (P05) 
Therapists mentioned that audio-only sessions are even shorter than video sessions. Although some interventions, such as expressive art therapies or trauma work, are difficult to reconfigure to a telehealth platform, the therapists we interviewed are still focusing on re-imagining interventions so that they can be adapted to the platform they are using.

\subsection{There are more distractions and therapists have to be more engaging}

Part of the reason why sessions are shorter is because of extra distractions, which range from caregivers having to watch children during their session time to children wanting to play games instead of attending therapy online. These distractions are typically easier to control in a therapy room. The therapists talked about how certain age groups appear to be more challenging to engage through telehealth platforms, particularly young children. P10 described it as: "my youngest clients really couldn't do the work that we were doing together. It did not seem like a good fit for teletherapy. I did have a couple of sessions with one of my 12-year-olds, but it just didn't... I don't have the skills necessary to do that."

Most of the child therapists expressed frustrations at the difficulties of getting young clients to focus on the session, especially since many of them preferred to watch TV and/or play video games. Some of this was attributed to boredom because of the limited interventions that therapists could do on both video and audio platforms, especially during the early months of the pandemic:

I had another kid who pulled out their phone and was trying to watch a TV show while we were talking and they didn't turn the volume down at all. So I was like, I can hear that. I can see you looking at your phone. So a lot of the activities have gone well, but with limitations. Kids get bored and it's easier for them to disengage with me. I feel like kids also, like, you know, we've played charades for the last three weeks. What else can we do? And I'm like, well, I'm kind of limited in what I have at this point. (P03)

This was especially true of clients who opted for audio-only sessions, as described by P05:

A lot of kids can't focus on the phone for more than half an hour. And sometimes, it's like a little 15-minute check-in and they just keep kind of giving me monosyllables and really they just want to go back to playing your video game, you know? And it's kind of a challenge. (P05)

Therapists needed to decide in these situations whether or not teletherapy was an appropriate medium for clients who do not seem engaged in therapy. Our informants talked about some clients not being appropriate for teletherapy, especially those with attention problems. This relates back to being able to create a safe and calming space, something that can be challenging to do when the space is not within the therapist's control.

I think that it's harder for me with clients who have like like maybe ADHD or like any kind of sensory issues, like tele-health is not appropriate, especially because like, if I'm not in a very controlled environment, like in a tight room where there are some outdoor sounds that I can't control because I'm working from home. (P12)

Some therapists tried to use online games to engage clients, but they expressed concerns regarding sending clients to a third-party website to play a game. Most of these websites contained ads that were unpredictable and may not be appropriate for clients of a certain age. Furthermore, with some websites, clients had to create their own account in order to play the game. P01 wished that some of the platforms either had games incorporated within them or that there could be a way to send a client a link to a safe, controlled website to play games and where the client would not have to pay to join. 
If there was some way to work with some of the online game things that they could incorporate in so we didn't have to send a separate link-that it was something that was a platform that was, you know, set for therapists to use that if we had an account, 'cause some of these, it requires the other person to create an account, and there's one out there that has a whole bunch of games and it's a paid thing, which I wouldn't mind, you know, if I could set up an account and do the pay thing and I could share screen and do the game that way. But the other person, they have to set up an account too and they have to pay for it. I'm not going to ask my clients to do that. (P01)

There are also more practical issues with engaging clients by using games, such as connectivity issues, device limitations (i.e., most clients use a device with a small screen which makes it challenging to play a game or screen share while on a video session), and limited technical literacy.

While therapists talked mainly about how difficult it is to engage children, there were some that also talked about facing this problem with adult clients. P07, who was using a video-based platform, talks about having to set boundaries with her adult client who seems distracted during their sessions:

The problem with using a platform, and I have had this happen a couple times, is that people feel that they can do whatever they want to do while they're on the phone. I have one client, we always meet on her smartphone and she feels that she can put her makeup on. Well, we're talking yesterday, she was actually going to drive to an appointment that she had while she was in session with me and I ended. I just ended it. And I'm-I need to be more assertive about saying I am fully present here with you, you be fully present with me. You know, if you are outside. That's fine. If you want to walk, while we're meeting on your smartphone, that's fine, but I expect your full attention. (P07)

Therapists are having to establish boundaries with their clients to ensure that the clients are "fully present." One therapist explained feeling a "lack of control" over the distractions, especially since many of these distractions are a direct consequence of the client being in another physical location.

\subsection{Therapists have new insight into the lives of their clients}

While therapists are having to figure out how to deal with these new distractions, there are also elements of teletherapy that offer new insights into how their clients act in their home environment.

Therapists reflected on how teletherapy has "opened up" their clients' world. Therapists have new insight into clients' interactions with their family members or housemates. For example, P03 talked about how she was able to get a better understanding of a client's relationship dynamics with their siblings:

It's been interesting because I feel like I've gotten a much better view of their home life and what their house looks like, what their family interactions are like, just 'cause people are there in the background. Or I've done some teletherapy scavenger hunts with some kids that's shown me their house and their room. Or this one kid in particular, we ended up having a pretty good talk earlier this week about like what it's been like being home with her siblings all the time. And now that I've seen a few of those family interactions, a little more in depth, I can comment on them a little bit more and say like, "Hey, that doesn't seem like age-appropriate behavior. Maybe we can talk about that since it just happened as I called." So that's been productive with a couple of my kids. I think it's kind of opened up their worlds to me. (P03)

Another therapist talked about how some therapeutic techniques are more effective in the home environment, especially when it relates to anxiety. Therapists are able to target certain behaviors 
where they occur, leading to more in-the-moment interventions. P05 talked about how one of her clients diagnosed with obsessive-compulsive disorder (OCD) experiences many of his compulsive behaviors when he is at home. P05 was able to better understand the client's triggers and was able to work through anxiety-reduction techniques while on a video session with the client:

It's been kind of an interesting opportunity for him because we are doing like some exposure and response prevention in his home, which is like where a lot of his triggers are the worst for, for his compulsion. So that's actually been kind of cool. (P05)

Other therapists talked about how being in the home environment has strengthened the therapeutic relationship with their clients. Clients are able to share aspects of their lives, whether it is showing their therapist their space or sharing pets or treasured items.

I have one client. She has a lot of animals. She's on a farm. And, um, that's something that she really likes. We usually do our sessions outside, she'll do them like in the barn and like the animals are kind of around her. That was really helpful. But I think, just in general for her, I think it was last week she had like a chicken on her shoulder, and she was showing me this chicken. And so, I think just for her, it's a lot easier to kind of be like, "Welcome to my world. This is how my life is," rather than sitting in an office and trying to kind of explain it. She can show it and things like that. And, so I think that's helped. (P06)

This blurring of boundaries is leading to a better understanding of what their clients' day-to-day lives look like, but it is also generating questions of whether therapists should interfere with certain aspects. A popular question among therapists was whether clients should be allowed to drink alcoholic beverages during their session time. Are therapists allowed to regulate what the client does in their home? Another participant mentioned having to get a client's partner to sign a consent form since they were listening and participating in their partner's session.

I'm having partners jump in and then I'm like, I gotta get a release signed for that. But probably, it makes it more systematic and I'm a systems-based therapist. Like, a client I have, I have one couple where I just see one of them and I've never actually physically seen the other one, but the client will say something and their partner will be like, "Well, that's wrong." So, it's almost like you get a little bit better idea of what's going on because you don't just have one person telling you things, because you're experiencing their life with them in real time. $(\mathrm{P} 08)$

Therapists have more information they have to take into consideration; some of this information leads to developing a better understanding of the client's experience, while other information raises potential ethical questions.

\subsection{A lack of relational cues are making the work feel harder}

Despite having access to more information, therapists are still missing important information that they rely on during their session: body language. Therapists rely on body language to understand how the client is feeling and/or reacting to session content and to assess a client's emotional state. Teletherapy has made it difficult for therapists to use these cues to guide their sessions. P07, who uses video in most of her sessions, describes how hard it is to use her intuition:

What changes in my sessions is that I go a lot by instinct and body language and what I can sense from a client. I tend to be intuitive. And so not being present in the same room makes it harder for me to use my intuition and get a sense of the person-that's how it's changed a lot for me. (P07)

Some therapists discussed having to spend more time and energy for session preparation, especially since the lack of visual cues makes it difficult to know how the client is reacting to the 
material being talked about in therapy. One of the therapists who does mostly audio-only sessions talked about how the lack of cues made the work feel harder for her:

I think I probably prep a lot more for my sessions now than I did, just because with the phone, it can be a little bit slower and kind of hard to carry that conversation, um, especially without those, you know, cues and things like that. And you can't really feed off of those things. So, just kind of really reflecting on the last session and being like, "Okay, how can we like build off of that." (P06)

11 out of 14 therapists stated that they would not want to continue doing teletherapy after the pandemic unless a client specifically asked for it. P07 explained that she does not "think it's the most effective way to do therapy. I think that you just are missing far too much of the nonverbal interaction." Many of the therapists who stated they did not enjoy teletherapy echoed similar concerns.

P08 talked about how she feels "handicapped" by the telehealth platforms, stating that she is missing crucial information. She shares the following story about not realizing that her client was crying due to lack of lighting from the client's side:

I had a client who was backlit by a window and I didn't realize she was crying. Like, I missed it. And like, what can I do if it takes me 20 minutes to realize someone's crying? And it makes me feel small. I'm a little bit handicapped in what I want to be doing. But, you know, you just make the best that you can. (P08)

In addition to the lack of visuals that therapists are used to, therapists are unable to use the therapeutic silence, which is a technique that is used to reflect on the material that is being presented during the session.

I know just from my individual client that I see, you miss those little body movements. You miss just that silence because there's that awkwardness, and I've heard this from my other interns at work. The silence when you're in the room with a person is so powerful, but when you're in front of a screen and you're just staring at each other, it's that awkwardness. So it kind of messes with that therapeutic bond that you have and it changes a little bit. (P04)

The lack of therapeutic silence is changing the cadence/rhythm of sessions. Most of the therapists indicated that instead of allowing the silence to occur, they are trying to fill the space with more activities.

It can be awkward. I mean, already it takes us like, you know, years to kind of overcome the like discomfort with the silence and then, you know, here we are again. But, you know, another thing I've heard is that, like, some therapists, one training I heard online with suggested to maybe do like worksheets or something together. So that we're, you know, the clients, we're not just like kind of staring at each other. In the room, we can look around the room or look out the window. (P11)

The therapists we interviewed are attempting to fill in the relational cues gap by either engaging in more activities or by trying to cope with the lack of communication of nonverbal behaviors. Therapists miss working in a physical space where they are able to take 'mini breaks' from gazing at the client. P11 remarked that looking away from the client could imply that the therapist is not engaged or busy with something else, so she tries to maintain eye contact with the camera to ensure that the client knows that therapist is "present."

\subsection{Teletherapy is exhausting and emotional support for therapists is different now}

While therapists are being creative and flexible in adapting their therapeutic techniques online, they also talked about how this extra cognitive labor is making them feel exhausted. P01 explained it as "we're so focused all the time and I know I sort of look off every now and then, but I mean you're

Proc. ACM Hum.-Comput. Interact., Vol. 5, No. CSCW2, Article 364. Publication date: October 2021. 
constantly on and it is absolutely exhausting." P06 talked about how she is "using even more brain power." P04 summarizes it well:

The challenge of online versus in-person is you having to process things different in your mind. I think that's the exhausting part. I wish I would have understood that ahead of time how tiring it was going to be. (P04)

In addition to therapists having to keep track of more information when conducting telehealth sessions, they also have a greater awareness of themselves through their own video representation. P06 explained this as follows:

I think I'm hyper-aware of how I'm looking, which I think probably has helped some because there's probably some things that I do that, I'm like, "Oh, I don't think I realized that that's how I looked while I was doing that." But then, at the same time, sometimes I get so distracted by thinking how this is looking to my client. (P06)

Although this information can be helpful for therapists, it calls attention to how they are using their face to convey information. Some of the therapists talked about feeling uncomfortable with having to look at themselves, stating that it can be distracting and difficult to feel "fully present" (P04).

All of this additional information has led to therapists making changes to their daily schedule to be able to maintain their stamina throughout their day. Even therapists who had previous experience with teletherapy talked about how they have had to learn to pace themselves. P12, who has been offering telehealth sessions for 3 years, stated that "the hardest part about adjusting to tele-health only has been regulating how much I work because it just feels like, Oh, I'm home. I can just work as much as possible. And that wasn't helpful."

Emotional support for the therapists themselves also feels and looks different. Many of the therapists are used to receiving support from the people around the office. But now that everyone is working online, therapists need to be intentional about reaching out for support. P03 talked about the "natural breaks" within a working day, where therapists "have 10 minutes between our next client so like, let's say hi and talk, and then we'll go to our next client." P10 talked about missing those impromptu interactions, stating that she has to "intentional about reaching out for advice and support."

P03 talked about the difficulties of having to be intentional about reaching out, stating that "it's also been exhausting to have another video session, another video call." There seems to be a trade-off between reaching out for help and also getting some distance from the technology. Some of our participants talked about how instead of talking to other therapists online, they are choosing to take walks outside or to find some quiet spaces where they can be away from their screens.

\section{DISCUSSION}

So I mean it was hard at first, especially where I was like, well, I had all these activities and then I have to throw them out the window and try something new or try and figure out how to adapt them. The first few weeks, I spent a lot of time and energy figuring out activities... I've like have MacGyvered some different things to work, but some kids respond better than others. (P03)

In this section, we discuss how therapists had to reimagine the work of therapy to relocate it to a telehealth platform. In particular, we discuss how relocating to the client's home environment via a telehealth platform changed how therapists envisioned the therapeutic alliance and how this shift in setting caused therapists to creatively retool their therapeutic interventions. We conclude this section by considering the costs of such relocation, both in terms of access to mental health services and in terms of therapists' workload and ability to cope with making this transition. 


\subsection{Relocating the therapeutic alliance}

The therapeutic alliance, which is the deep, collaborative relationship established between a client and a therapist [28], has been able to transcend the physicality of therapy space. Therapists are, in fact, able to use their position in the client's environment to develop a stronger therapeutic alliance. While previous work has shown that therapists have concerns about teletherapy due to perceived difficulties in establishing a therapeutic alliance online [14,53], our study suggests that the shift to teletherapy is creating deeper relationships where therapists are able to learn more about and reference items, people, pets, etc. that are meaningful to the client. There are certain trade-offs though, as this shift in space negatively affected aspects of nonverbal communication, another major component of the therapeutic alliance.

The challenges with conveying nonverbal cues via telehealth platforms is especially detrimental to trauma-related work. Therapists rely on non-verbal communication to monitor and help the client regulate their emotions and in creating a safe space, especially when it relates to discussing difficult subjects $[25,34,50,58,73]$. A common thread among the therapists we interviewed suggested that trauma work that is highly dependent on helping the client stay emotionally regulated cannot take place online. According to researchers, the ability to transfer certain interventions online is highly dependent on how competent a therapist feels in their skills to do this [15]. This raises the following questions: Will specialized training help therapists feel more comfortable in engaging in remote trauma work with their clients? How can a telehealth platform be improved to allow the creation of a safe space that closely mimics that of a therapy room? Understanding more about how to create a safe space in an abstract, virtual space is integral in supporting the work practices of therapists.

Even though some aspects of trauma work do not seem to translate to teletherapy, therapists still report feeling a strong therapeutic alliance, even for some audio-only sessions where there are no additional cues available. With audio-only sessions, therapists are still able to utilize the client's environment to help the client make connections and insights. Some researchers suggest that clients may value the anonymity provided by phone sessions, even if it results in a loss of nonverbal cues $[20,39,45,45]$. This insight was supported by the experiences of therapists who work with clients in rural settings and those who work with the trans community. Most of the therapists we spoke with talked about offering clients the option to do video sessions on different platforms or audio-only sessions, depending on their preferences. This flexibility is integral to the therapeutic alliance; by having access to multiple platforms, therapists are able to meet the client's need and preference. The different features of the platforms, therefore, become an important mediator in establishing a therapeutic relationship.

\subsection{Relocating therapeutic interventions}

Teletherapy has provided new opportunities for therapists, but it has taken some work, resiliency, and creativity to transition the therapy room to a virtual space. The process of relocating certain therapeutic interventions has been particularly challenging, described as a "MacGyvering" or reimagining previously established ways of doing things. This stands in stark contrast to previous research that indicates that therapeutic interventions can easily be adapted to online platforms [27, $32,46]$. There are tensions between what the therapists wish they could do on the platform and what the platform is capable of doing. In other words, therapists desire a sense of agency when interacting with the platform [47]. The therapists now have the added work of negotiating with these limitations to figure out what features will help them achieve their goals or reconfigure their original plan. For example, $\mathrm{P} 2$ talked about wanting to do music therapy interventions online, but the connection lag and the inability of the platform to play sound from both her computer and 
her client's computer made it impossible to engage in traditional music therapy interventions. She reoriented her work through the platform by focusing on turn-taking music therapy techniques instead.

Even though some interventions require additional work, there are some that appear to be wellsituated for teletherapy. The therapist's presence in the home environment means that they are able to help clients address problems in the moment, particularly if the client's emotional or behavioral difficulties are triggered in or by the home environment. These "in-the-moment" interventions, or ecological momentary interventions [36], can be particularly effective because they occur in real-time in a natural setting. This relocation to the client's home offers opportunities that are not possible in a mental health clinic or office, highlighting a superior affordance of teletherapy.

\subsection{The costs of relocation}

Most of the therapists that we interviewed agree that teletherapy is here to stay, and that it will be an option for clients moving forward. The sentiment among researchers is similar-they believe that the 2020 pandemic is accelerating changes in the delivery of mental health, not someday in the future but here and now [78, 80]. It is imperative to think of the costs of doing teletherapy, both to the clients who may be left out and to the therapists who feel overwhelmed by the relocation of work.

First, we need to consider who we may be missing by relocating telehealth online. Although teletherapy can address barriers to care $[10,14,15]$, there are some inequities that can be exacerbated by teletherapy. For example, those clients who have the technology resources, who are more technologically literate, and who have access to physical space will be likely to receive the most benefits from teletherapy. As described by the therapists we interviewed, there are certain clients from rural areas or low socioeconomic backgrounds who may participate in teletherapy but only in a limited way. For example, P05 spoke about how some of her low-income clients were reluctant to do remote sessions because they did not have a safe and private space in their home. P07 describes it as follows: "I think it's part of that equitable care. Everyone deserves to have access to this care and it shouldn't be just because the infrastructure isn't there. But these people [those in rural areas] deserve a different kind of service." Another participant, who works primarily with the trans community, also brought up the importance of having diverse and inclusive telehealth platform creators. She shared how one of her clients felt "erased" by the technology they were using for telehealth delivery after it offered only two options for gender: male and female. While teletherapy can create opportunities for better mental health access $[10,14,15]$, researchers and practitioners have to be cognizant of who may be marginalized through the use of these technologies, especially given the critical needs of these populations for mental health services.

Second, because of the situated nature of teletherapy, therapists have access to much more information about their clients than they would in a traditional therapy setting. The therapists we interviewed expressed feeling overloaded with information, having to "use more brain power." We need to consider burnout as one of the costs of teletherapy.

We have been getting emails from the owner of our company saying "We have an incredible amount of people trying to get in so we need you guys to take on more cases." And so, we're all kind of going "can we take on more cases versus should we take on more?" We've had multiple therapists just up and quit. (P03)

Even prior to the COVID-19 pandemic, mental health therapists were at high risk of burnout due to the nature of their job [21, 64, 83]. Researchers suspect that the COVID-19 pandemic will accelerate the burnout of mental health providers [42], citing the need for the development of helpful interventions for the providers. In a large systematic review, researchers found that the 
prevalence of emotional exhaustion, a core dimension of burnout, was reported by approximately 40 percent of mental health providers [64]. All but one of the therapists we spoke to reported high levels of exhaustion since the shift to teletherapy. While positive work relationships can help combat burnout [21], some therapists are having difficulties connecting with each other due to 'screen fatigue,' opting instead to take breaks. Connecting with each other is an integral part of the work of therapists and the loss of the ability to process cases and find support may have devastating consequences. Telehealth offers many opportunities for connecting, but designers must consider other methods to mitigate exhaustion and focus on creating a more nourishing and restoring experience. The process of onboarding, itself, seems laborious and taxing. How can we improve on this to onboard therapists more quickly? If not, the consequences can be devastating for the work practices of therapists.

\subsection{The layered-ness of relocating therapeutic work}

Unlike other forms of work whose transition from physical to digital has previously been studied by researchers in the CSCW community, the relocation of therapeutic work offers a particularly challenging 'edge case.' This is due, in large part, to the multiple layers of work that are implicated in relocating therapy online: the establishment of a safe space in which to carry out the work, the creation and maintenance of a therapeutic alliance between therapist and client that relies on the close reading of physical posture and facial expression, and the need for therapists to be able to rely on interaction with one another between sessions in order to process cases and give and receive necessary emotional support. The telehealth platforms adopted and appropriated by therapists on short notice provided only (relatively) rudimentary support for carrying out face-to-face conversations, not the richness and nuance required to support the multiplicity of layers of work practice involved in treating mental health. Although our interviews revealed some surprisingly positive outcomes from this pivot from the physical world to teletherapy, we see both opportunities for designers to better support other layers of work practice in telehealth platforms and evidence of therapists' creativity and resilience in bending existing systems' capabilities to work as well as they have during such a challenging time.

\section{DESIGN AND RESEARCH OPPORTUNITIES}

Based on the experiences of the therapists in our study, we have identified several opportunities to better support teletherapy through design and catalyze future research in this domain. These opportunities are neither meant to be exhaustive nor generalizable to all therapeutic situations, but point to new directions for evolving telehealth platforms. Although some of these design and research opportunities may apply to other forms of computer-mediated communication, they are particularly important for establishing a safe space and supporting a therapeutic environment online.

\subsection{Supporting the therapeutic alliance}

Because of the limited visual information the therapist has about the client, especially when clients are on a mobile device and/or moving around their space, the therapists we interviewed reported difficulties in interpreting the client's body language and assessing to what extent the client was grounded or engaged in the session. Designers might be able to better support this important facet of the therapeutic alliance by providing a suite of options to optimize the audio/video in varying ways depending on the content of the session, the client's needs, and/or the robustness of the connection. For example, the system could provide an option to to prioritize audio and downsample video, which might be preferable when sessions are fraught with connectivity issues, or an option to adjust the video during sessions when a client might be sitting next to a window or 
in a darkened room, ensuring that the therapist can better assess a client's facial expressions even under sub-optimal lighting conditions.

Additionally, since there is no shared, physical therapy room, therapists expressed a need to work with clients in being intentional about how they construct the virtual space and how they leverage the environment around them. This can be difficult, particularly with clients who do not have a safe space, who lack privacy in their space, or who frequently experience connectivity issues. Some of the therapists we interviewed shared that they and their clients had co-created signals to provide cues to each other about changes in their environment, since the context of a teletherapy session was much more dynamic and unpredictable than in an office-using a hand sign, for example, if someone had stepped into the room so that the therapist could change the topic to something innocuous. Designers might explore adding a suite of iconographic and/or auditory communication shortcuts to teletherapy platforms (perhaps similar to the 'reaction' emoji available in contemporary office telework environments, but more readily available on-screen and perhaps using more flexibly appropriable imagery). In addition to communication shortcuts indicating that 'someone stepped into earshot,' one might also offer ways for participants to indicate 'distracted by other notifications online; give me a second' or 'I need just a moment to collect myself.' More research would be needed to explore whether these genres of signals are generalizable or flexibly appropriable enough across therapeutic contexts and whether or not they could be socially negotiated in affirming enough ways to be helpful.

Future research might also explore the unique affordances of mobile phones for offering enriched support for the therapeutic alliance. The majority of therapists in this study reported that their clients attended sessions on their mobile phones, a marked difference from how video conferencing software is typically assumed to be used in work and learning environments. Empirical studies and design research could also focus on exploring how mobile phone sensors (e.g., accelerometer-based tremor detection [52]; dynamic stress assessment based on changes in the volume, pitch, and speed of speech [49]; and/or changes in the physical or social environment via image processing from the device's camera(s) [37] or audio processing from its microphone [66]) could be leveraged by teletherapy platforms to improve or enhance the therapeutic alliance in ways that are sensitive to the privacy and agency of both therapist and client.

\subsection{Supporting the diversity of therapeutic interventions}

The needs of therapists seemed to be dependent on the type of clients with whom they work, the types of interventions they employ, and their particular theoretical orientations, suggesting the need for differentiation of the features of the platform. For example, child therapists and expressive therapists appeared to have a more difficult time with the transition to teletherapy, particularly because it was more challenging to re-create some therapeutic interventions online. Therapists suggested that it would be helpful if the platforms used in these contexts included built-in games and activities to avoid the distractions and risks that come with linking to external sites, especially for minors. Designers might also explore options for teletherapy platforms to offer different kinds of 'ambiance' that therapists or clients could select. For example, the ability to control lighting might help clients who are easily stimulated or might help with interventions involving meditation or enhance certain music/art therapy interventions. Through this differentiation of features, we could envision telehealth platforms being flexible and adaptable to the diversity of therapeutic interventions, rather than being deployed as 'one-size-fits-all' technologies.

\subsection{Supporting equity in teletherapy}

Telehealth platforms are often thought of as tools that can increase access to mental health [9, $20,56,71]$. However, researchers have found that teletherapy has not successfully reduced health 
disparities, particularly in vulnerable communities, due to various structural barriers $[59,65,70]$. The therapists we interviewed validated these findings, indicating that there were still some groups who they were not able to reach via online platforms, including but not limited to those who live in rural areas, those with severe mental illness, and those who are not comfortable using technology. Community informatics advocates, for example, might highlight the need for public computing facilities (e.g., rural libraries) to offer private, reservable computer access. Ralston et al. [70] have also recommended the use of health advocates that are trusted by the community to improve the reach of teletherapy in communities that may be hesitant to use technology for mental health care.

Designers must also ensure that populations are not marginalized by teletherapy platforms, for example, by providing more inclusive options for constructing one's own and viewing others' profiles. One of the advantages of being online is that individuals can feel empowered to represent parts of their identity that they want to share with others [82]. For example, some teletherapy platforms currently limit identity representation by only offering two gender options in their integrated forms. Ensuring that these features are more inclusive may be technically simple but doing so stands to have a powerful impact. This opportunity for design and research is likely to be increasingly important in the event that therapists move toward experimenting with offering more group or family therapy modalities online.

One of the more critical directions for future research, then, are studies that explore the experiences with or often-structural barriers to the use of teletherapy by these populations of clients and the therapists and community agencies who serve them.

\subsection{Supporting therapist self care}

The therapists we interviewed described significant fatigue due to the increased attention and energy that they had to allocate to adapting their practices. Burnout among therapists is high, even without the added burden of conducting teletherapy, and particularly for those therapists who work at community organizations that service vulnerable communities [21, 74]. Empirical research is desperately needed to understand the proper 'dosing' of teletherapy so that organizations can develop supportive policies about how to integrate and moderate (or limit) the use of teletherapy in a hybrid therapy practice moving forward.

While most forms of therapist self-care likely need to happen offline and not through a teletherapy platform, therapists did highlight one small-scale self-care practice that was difficult to relocate online: the 'mini-break.' Mini-breaks typically occur during face-to-face sessions when the therapist is able to temporarily shift their gaze to other parts of the environment without the client feeling a sense of disengagement on the therapist's behalf. The therapists we interviewed felt like it was important to maintain their gaze on camera in order to establish a safe space for the client; however, they also reported experiencing more fatigue by not feeling the same ability to take those visual mini-breaks. Some therapists reported feeling exhausted by not only maintaining eye contact with the client, but also by having their own self-view appear on their display. While there are existing capabilities to turn off self-view, some of the therapists reported difficulties in finding that feature, with some resorting to putting a physical sticky note over their own video. While it may be difficult to fully replicate the 'mini-break' online, there may be different ways to support this self-care practice. For example, the option to switch from face-to-face interaction into virtual therapy rooms that include avatars might allow the therapist and client to interact with one another in the third person. Alternatively, it may be possible to break up face-to-face conversation time with tools that promote active or generative engagement, such as electronic whiteboards that enable shared writing or drawing during the session. These types of online interactions could be a way for therapists to reap the benefits of 'mini-breaks' during their sessions without compromising the 
integrity of the therapeutic alliance. More empirical research can be conducted to determine if these functionalities are helpful in mitigating burnout and supporting self-care practices for therapists.

\section{LIMITATIONS AND FUTURE WORK}

Our sample and data do have some limitations. We recruited our sample based on our professional networks $(n=3)$ and through social media $(n=11)$, which might have skewed the types of therapists who participated in our study. The 2020 pandemic also led to unique challenges in recruitment, such as limited availability due to increased responsibilities resulting from school closures or increased pressures due to economic effects. In particular, therapists with school-aged children are likely underrepresented in our sample. While we strove to interview therapists who work with diverse client populations, there were client populations not represented by the therapists in this study. For example, we had difficulties recruiting therapists who worked with individuals with cognitive difficulties or those who work with clients who have disabilities that may affect their interactions with online platforms. Despite these limitations, our analysis did achieve theoretical saturation and a member check affirmed its resonance across a wider breadth of therapists than prior research; we anticipate that the knowledge gleaned will be transferable to therapists beyond our sample. Future work would also be valued in exploring the transferability of these findings to other domains of remote collaboration that require a deep and personal relationship.

Additionally, the unique circumstances of the pandemic may have led to added challenges in adapting to the telehealth platforms, making it difficult to tease apart difficulties due to the telehealth platforms and difficulties of the pandemic. The extreme fatigue, for example, reported by nearly all participants likely has some basis in the pervasive use of telehealth platforms and some basis in the chronic fatigue involved in coping with the uncertainty and overwhelmingness of the pandemic, itself. Future research is needed to tease apart the different factors.

\section{CONCLUSION}

I have a number of people that have just been so thankful that they can still meet with me somehow. And I, I think that says a lot for how important therapy is right now. There's a huge mental health crisis that's looming right on the doorstep. And so I think that the more proficient we are at teletherapy, the better because more people are going to need services before we can see them in person. (P07)

The adoption and appropriation of telehealth platforms by mental health therapists following the mandatory social distancing protocols in response to COVID-19 catalyzed an emergency transition to computer-supported therapeutic work for a generally reluctant class of professionals. Yet, both the nature and effects of the pandemic have made the use of telehealth platforms by therapists absolutely essential. In this research, we have contributed a more in-depth understanding of the implications of the relocation of this work-a qualitative empirical account of therapists' experiences moving their practices online; their interactions with the telehealth platforms that enabled them to do so; and the effects that this transition has had on their work practices, their relationships with their clients, and their ability to care for themselves and their professional colleagues.

Our findings revealed some positive aspects of this relocation of therapy online: for example, the therapists we interviewed were able to use telehealth platforms to leverage the client's home environment to deliver engaging interventions and to build strong, therapeutic relationships with their clients. Therapists' access to their clients' home environments, while raising ethical and privacy issues, were also helpful in providing them with more detailed and deeper in-the-moment information about their clients' symptoms and day-to-day lives. 
Despite these benefits, we found that there are complex challenges in and costs to using telehealth platforms-limitations to the effectiveness of some aspects of mental health care (e.g., treating trauma and 'reading' clients' body language) and the fact that use of these platforms can contribute to exhaustion and burnout for therapists. Finally, while telehealth can improve access to care, we discuss how it can also exacerbate inequalities for certain client populations.

The relocation of mental health services online serves as an edge-case study of the work required to adapt to remote work. Therapists are challenged to creatively and resiliently manage the relocation of two interdependent facets of therapeutic work online-building and maintaining the therapeutic alliance and creating effective therapeutic interventions-each of which has distinct opportunities and challenges. We presented a suite of design opportunities to help address some of the current limitations and offer possible enhancements to future telehealth platforms.

Prior to the COVID-19 pandemic, telehealth platforms had seen much slower adoption by mental health practitioners than in other healthcare domains. Yet the nature and effects of this pandemic have created an urgent need and a strong motivation for therapists to experiment with and become proficient in teletherapy. The role of the computer-supported cooperative work community should be central, moving forward, in building upon early empirical studies-such as this one-to design platforms that better resonate with the multilayered needs of therapists and their clients.

\section{ACKNOWLEDGMENTS}

We are indebted to the 14 therapists who made time in their already-overbooked schedules in the midst of a global pandemic to share their experiences with us. Thank you for helping with this research and for all the important and crucial work you do. We are also grateful to the therapists who we recruited but who modelled extraordinary self care by declining to participate. Many thanks to our CSCW reviewers for their support and constructive feedback on this work and to Janghee Cho, Shiva Darian, Melanie Sidwell, and Madhur Atreya for reading drafts of this work and for providing helpful feedback.

\section{REFERENCES}

[1] Ron Acierno, Daniel F Gros, Kenneth J Ruggiero, Melba A Hernandez-Tejada, Rebecca G Knapp, Carl W Lejuez, Wendy Muzzy, Christopher B Frueh, Leonard E Egede, and Peter W Tuerk. 2016. Behavioral activation and therapeutic exposure for posttraumatic stress disorder: A noninferiority trial of treatment delivered in person versus home-based telehealth. Depression and Anxiety 33, 5 (2016), 415-423.

[2] Steven J Ackerman and Mark J Hilsenroth. 2003. A review of therapist characteristics and techniques positively impacting the therapeutic alliance. Clinical Psychology Review 23, 1 (2003), 1-33.

[3] Mental Health America. 2020. COVID-19. https://mhanational.org/covid19

[4] Kristen E Anderson, Catherine E Byrne, Ross D Crosby, and Daniel Le Grange. 2017. Utilizing telehealth to deliver family-based treatment for adolescent anorexia nervosa. International fournal of Eating Disorders 50, 10 (2017), $1235-1238$.

[5] Catharina Tri Anni et al. 2018. School counselors' intention to use technology: The Technology Acceptance Model. Turkish Online Journal of Educational Technology-TOJET 17, 2 (2018), 120-124.

[6] APA. 2017. Ethical principles of psychologists and code of conduct. https:/www.apa.org/ethics/code/

[7] American Psychological Association. 2020. Psychologists embrace telehealth to prevent the spread of COVID19. https://www.apaservices.org/practice/legal/technology/psychologists-embrace-telehealth?_ga=2.3103600. 1572637174.1617985414-2103552600.1610734726

[8] Shashi Bahl, Ravi Pratap Singh, Mohd Javaid, Ibrahim Haleem Khan, Raju Vaishya, and Rajiv Suman. 2020. Telemedicine technologies for confronting COVID-19 pandemic: A review. fournal of Industrial Integration and Management 5, 4 (2020), 547--561.

[9] Azy Barak and John M Grohol. 2011. Current and future trends in internet-supported mental health interventions. Journal of Technology in Human Services 29, 3 (2011), 155-196.

[10] Sandra Benavides-Vaello, Anne Strode, and Beth C Sheeran. 2013. Using technology in the delivery of mental health and substance abuse treatment in rural communities: A review. The fournal of Behavioral Health Services \& Research 40, 1 (2013), 111-120. 
[11] Edward S Bordin. 1979. The generalizability of the psychoanalytic concept of the working alliance. Psychotherapy: Theory, Research \& Practice 16, 3 (1979), 252.

[12] Joseph Brand and Dean McKay. 2012. Telehealth approaches to obsessive-compulsive related disorders. Psychotherapy Research 22, 3 (2012), 306-316.

[13] Samantha K Brooks, Rebecca K Webster, Louise E Smith, Lisa Woodland, Simon Wessely, Neil Greenberg, and Gideon James Rubin. 2020. The psychological impact of quarantine and how to reduce it: Rapid review of the evidence. The Lancet 395 (2020), 912-920. Issue 10227.

[14] Sabrina Cipolletta and Damiano Mocellin. 2018. Online counseling: An exploratory survey of Italian psychologists' attitudes towards new ways of interaction. Psychotherapy Research 28, 6 (2018), 909-924.

[15] Stewart E Cooper, Linda F Campbell, and Sara Smucker Barnwell. 2019. Telepsychology: A primer for counseling psychologists. The Counseling Psychologist 47, 8 (2019), 1074-1114.

[16] Juliet Corbin and Anselm Strauss. 2014. Basics of qualitative research: Techniques and procedures for developing grounded theory (4th ed.). SAGE Publications, Thosand Oaks, CA.

[17] David Coyle, Gavin Doherty, Mark Matthews, and John Sharry. 2007. Computers in talk-based mental health interventions. Interacting with Computers 19, 4 (2007), 545-562.

[18] John W Creswell and Dana L Miller. 2000. Determining validity in qualitative inquiry. Theory into Practice 39, 3 (2000), 124-130.

[19] Eileen A Dombo, Lisa Kays, and Katelyn Weller. 2014. Clinical social work practice and technology: Personal, practical, regulatory, and ethical considerations for the twenty-first century. Social Work in Health Care 53, 9 (2014), $900-919$.

[20] Mitchell Dowling and Debra Rickwood. 2013. Online counseling and therapy for mental health problems: A systematic review of individual synchronous interventions using chat. fournal of Technology in Human Services 31, 1 (2013), 1-21.

[21] Kimberly C Dreison, Lauren Luther, Kelsey A Bonfils, Michael T Sliter, John H McGrew, and Michelle P Salyers. 2018. Job burnout in mental health providers: A meta-analysis of 35 years of intervention research. fournal of Occupational Health Psychology 23, 1 (2018), 18.

[22] Barry L Duncan, Scott D Miller, and Jacqueline A Sparks. 2011. The heroic client: A revolutionary way to improve effectiveness through client-directed, outcome-informed therapy. Jossey-Bass, San Francisco, CA.

[23] Anne G Ekeland, Alison Bowes, and Signe Flottorp. 2010. Effectiveness of telemedicine: A systematic review of reviews. International fournal of Medical Informatics 79, 11 (2010), 736-771.

[24] David M Erekson, Russell J Bailey, Kara Cattani, Sheilagh T Fox, and Melissa K Goates-Jones. 2020. Responding to the Covid-19 pandemic at a university counseling center: Administrative actions, client retention, and psychotherapy outcome. Counselling Psychology Quarterly (2020), 1-15.

[25] Heather A Faucett, Matthew L Lee, and Scott Carter. 2017. I should listen more: Real-time sensing and feedback of non-verbal communication in video telehealth. Proceedings of the ACM on Human-Computer Interaction 1, CSCW (2017), 1-19.

[26] Gretchen N Foley and Julie P Gentile. 2010. Nonverbal communication in psychotherapy. Psychiatry (Edgmont) 7, 6 (2010), 38.

[27] Beverly W Funderburk and Sheila Eyberg. 2011. Parent-child interaction therapy. In History of psychotherapy: Continuity and change. American Psychological Association, Washington, DC, 415-420.

[28] O Giotakos and E Papadomarkaki. 2016. Online Counselling: The prospect of a therapeutic connection. Psychiatriki 27, 2 (2016), 127-135.

[29] Jessica Gold. 2021. We need to talk about another pandemic mental health crisis: Therapist burnout. Forbes (Jan 2021). https://www.forbes.com/sites/jessicagold/2021/01/19/we-need-to-talk-about-another-pandemic-mental-healthcrisis-therapist-burnout/?sh=2278924d4d18

[30] Jonathan Grudin. 1994. Groupware and social dynamics: Eight challenges for developers. Commun. ACM 37, 1 (1994), 92-105.

[31] Rose Gunn, Melinda M Davis, Jennifer Hall, John Heintzman, John Muench, Brianna Smeds, Benjamin F Miller, William L Miller, Emma Gilchrist, Shandra Brown Levey, et al. 2015. Designing clinical space for the delivery of integrated behavioral health and primary care. The fournal of the American Board of Family Medicine 28, Supplement 1 (2015), S52-S62.

[32] Robin H Gurwitch, Hanan Salem, Melanie M Nelson, and Jonathan S Comer. 2020. Leveraging parent-child interaction therapy and telehealth capacities to address the unique needs of young children during the COVID-19 public health crisis. Psychological Trauma: Theory, Research, Practice, and Policy 12, S1 (2020), S82-S84.

[33] Judith A Hall, Jinni A Harrigan, and Robert Rosenthal. 1995. Nonverbal behavior in clinician-patient interaction. Applied and Preventive Psychology 4, 1 (1995), 21-37.

[34] Stephen G Henry, Andrea Fuhrel-Forbis, Mary AM Rogers, and Susan Eggly. 2012. Association between nonverbal communication during clinical interactions and outcomes: A systematic review and meta-analysis. Patient Education and Counseling 86, 3 (2012), 297-315. 
[35] Dean H Hepworth, Ronald H Rooney, Glenda D Rooney, Kimberly Strom-Gottfried, and JoAnn Larsen. 2009. Direct social work practice: Theory and skills. Pacific Grove Thompson Brooks, Belmont, CA.

[36] Kristin E Heron and Joshua M Smyth. 2010. Ecological momentary interventions: Incorporating mobile technology into psychosocial and health behaviour treatments. British fournal of Health Psychology 15, 1 (2010), 1-39.

[37] Steve Hodges, Lyndsay Williams, Emma Berry, Shahram Izadi, James Srinivasan, Alex Butler, Gavin Smyth, Narinder Kapur, and Ken Wood. 2006. SenseCam: A retrospective memory aid. In International Conference on Ubiquitous Computing. Springer, Berlin, 177-193.

[38] Ursula Huws, Werner B Robinson, and Simon Robinson. 1990. Telework: Towards the elusive office. John Wiley \& Sons, Inc., Chichester.

[39] Annie Irvine, Paul Drew, Peter Bower, Helen Brooks, Judith Gellatly, Christopher J Armitage, Michael Barkham, Dean McMillan, and Penny Bee. 2020. Are there interactional differences between telephone and face-to-face psychological therapy? A systematic review of comparative studies. Fournal of Affective Disorders 265 (2020), 120-131.

[40] Nalita James. 2016. Using email interviews in qualitative educational research: Creating space to think and time to talk. International fournal of Qualitative Studies in Education 29, 2 (2016), 150-163.

[41] Kristina Jaskyte. 2011. Predictors of administrative and technological innovations in nonprofit organizations. Public Administration Review 71, 1 (2011), 77-86.

[42] Gunjan Joshi and Ginni Sharma. 2020. Burnout: A risk factor amongst mental health professionals during COVID-19. Asian Journal of Psychiatry 54 (2020), 102300.

[43] Anne Klee, Meaghan Stacy, Robert Rosenheck, Laurie Harkness, and Jack Tsai. 2016. Interest in technology-based therapies hampered by access: A survey of veterans with serious mental illnesses. Psychiatric Rehabilitation fournal 39, 2 (2016), 173-179.

[44] Lambros Lazuras and Anna Dokou. 2016. Mental health professionals' acceptance of online counseling. Technology in Society 44 (2016), 10-14.

[45] Todd Leibert and James Archer Jr. 2006. An exploratory study of client perceptions of internet counseling and the therapeutic alliance. Fournal of Mental Health Counseling 28, 1 (2006), 69-83.

[46] Charles E Levy, Heather Spooner, Jennifer B Lee, Jill Sonke, Keith Myers, and Elizabeth Snow. 2018. Telehealth-based creative arts therapy: Transforming mental health and rehabilitation care for rural veterans. The Arts in Psychotherapy 57 (2018), 20-26.

[47] Hannah Limerick, David Coyle, and James W Moore. 2014. The experience of agency in human-computer interactions: A review. Frontiers in Human Neuroscience 8 (2014), 643.

[48] Luona Lin, Andrew Nigrinis, Peggy Christidis, and Karen Stamm. 2015. Demographics of the U.S. psychology workforce: Findings from the American Community Survey. https://www.apa.org/workforce/publications/13demographics/report.pdf

[49] Hong Lu, Denise Frauendorfer, Mashfiqui Rabbi, Marianne Schmid Mast, Gokul T. Chittaranjan, Andrew T. Campbell, Daniel Gatica-Perez, and Tanzeem Choudhury. 2012. StressSense: Detecting stress in unconstrained acoustic environments using smartphones. In Proceedings of the 2012 ACM Conference on Ubiquitous Computing (Pittsburgh, Pennsylvania) (UbiComp '12). ACM Press, New York, NY, 351-360.

[50] Christine R Ludy-Dobson and Bruce D Perry. 2010. The role of healthy relational interactions in buffering the impact of childhood trauma. In Working with children to heal interpersonal trauma: The power of play, Eliana Gil (Ed.). Guilford Press, New York, NY, 26-43.

[51] Jessica Lynn Campbell. 2020. A mixed-methods approach to evaluating the usability of telemedicine communications. In Proceedings of the 38th ACM International Conference on Design of Communication. ACM, New York, 1-6.

[52] Mark Matthews, Stephen Voida, Saeed Abdullah, Gavin Doherty, Tanzeem Choudhury, Sangha Im, and Geri Gay. 2015. In Situ Design for Mental Illness: Considering the Pathology of Bipolar Disorder in MHealth Design. In Proceedings of the 17th International Conference on Human-Computer Interaction with Mobile Devices and Services (Copenhagen, Denmark) (MobileHCI '15). ACM Press, New York, NY, 86-97.

[53] Michael James McClellan, Dan Florell, Jerry Palmer, and Chris Kidder. 2020. Clinician telehealth attitudes in a rural community mental health center setting. Fournal of Rural Mental Health 44, 1 (2020), 62

[54] Judith LM McCoyd and Toba Schwaber Kerson. 2006. Conducting intensive interviews using email: A serendipitous comparative opportunity. Qualitative Social Work 5, 3 (2006), 389-406.

[55] John McNutt, Chao Guo, Lauri Goldkind, and Seongho An. 2018. Technology in nonprofit organizations and voluntary action. Voluntaristics Review 3, 1 (2018), 1-63.

[56] Faye Mishna, Marion Bogo, and Jami-Leigh Sawyer. 2015. Cyber counseling: Illuminating benefits and challenges. Clinical Social Work Journal 43, 2 (2015), 169-178.

[57] Emily Mitchell. 2020. "Much more than second best": Therapists' experiences of videoconferencing psychotherapy. European fournal for Qualitative Research in Psychotherapy 10 (2020), 121-135. 
[58] Jakub Mlynář, Esther González-Martínez, and Denis Lalanne. 2018. Situated organization of video-mediated interaction A review of ethnomethodological and conversation analytic studies. Interacting with Computers 30, 2 (2018), 73-84.

[59] Carole R Myers. 2019. Using telehealth to remediate rural mental health and healthcare disparities. Issues in Mental Health Nursing 40, 3 (2019), 233-239.

[60] Jocelyn K Novella, Kok-Mun Ng, and Jessica Samuolis. 2020. A comparison of online and in-person counseling outcomes using solution-focused brief therapy for college students with anxiety. Fournal of American College Health (2020), 1-8.

[61] U.S. Department of Health \& Human Services. 2020. Telehealth: Delivering care safely during COVID-19. https: //www.hhs.gov/coronavirus/telehealth/index.html

[62] Gary M Olson and Judith S Olson. 2000. Distance matters. Human-Computer Interaction 15, 2-3 (2000), 139-178.

[63] Janyce E Osenbach, Karen M O’Brien, Matthew Mishkind, and Derek J Smolenski. 2013. Synchronous telehealth technologies in psychotherapy for depression: A meta-analysis. Depression and Anxiety 30, 11 (2013), 1058-1067.

[64] Karen O'Connor, Deirdre Muller Neff, and Steve Pitman. 2018. Burnout in mental health professionals: A systematic review and meta-analysis of prevalence and determinants. European Psychiatry 53 (2018), 74-99.

[65] Jeongyoung Park, Clese Erikson, Xinxin Han, and Preeti Iyer. 2018. Are state telehealth policies associated with the use of telehealth services among underserved populations? Health Affairs 37, 12 (2018), 2060-2068.

[66] Alex (Sandy) Pentland. 2008. Honest signals: How they shape our world. MIT Press, Cambridge, MA.

[67] Bruce D Perry. 2009. Examining child maltreatment through a neurodevelopmental lens: Clinical applications of the neurosequential model of therapeutics. Journal of Loss and Trauma 14, 4 (2009), 240-255.

[68] Casey Pierce, Robin Brewer, Elizabeth Morris, and Madia Essiet. 2018. Computer-supported health and well-being services: A systems approach to telehealth and coaching systems. In Proceedings of the 12th EAI International Conference on Pervasive Computing Technologies for Healthcare. ACM, New York, 384-388.

[69] Rafael Zambelli Pinto, Manuela L Ferreira, Vinicius C Oliveira, Marcia R Franco, Roger Adams, Christopher G Maher, and Paulo H Ferreira. 2012. Patient-centred communication is associated with positive therapeutic alliance: A systematic review. Journal of Physiotherapy 58, 2 (2012), 77-87.

[70] Allura L Ralston, Arthur R Andrews III, and Debra A Hope. 2019. Fulfilling the promise of mental health technology to reduce public health disparities: Review and research agenda. Clinical Psychology: Science and Practice 26, 1 (2019), e12277.

[71] Derek Richards and Noemi Viganó. 2013. Online counseling: A narrative and critical review of the literature. Journal of Clinical Psychology 69, 9 (2013), 994-1011.

[72] Paul E Ruskin, Michele Silver-Aylaian, Mitchel A Kling, Susan A Reed, Douglas D Bradham, J Richard Hebel, David Barrett, Frederick Knowles III, and Peter Hauser. 2004. Treatment outcomes in depression: Comparison of remote treatment through telepsychiatry to in-person treatment. American fournal of Psychiatry 161, 8 (2004), 1471-1476.

[73] Allison Sauppé and Bilge Mutlu. 2014. How social cues shape task coordination and communication. In Proceedings of the 17th ACM conference on Computer Supported Cooperative Work \& Social Computing. ACM, New York, 97-108.

[74] Wilmar B Schaufeli, Michael P Leiter, and Christina Maslach. 2009. Burnout: 35 years of research and practice. Career Development International 14, 3 (2009), 204-220.

[75] Irving Seidman. 2006. Interviewing as qualitative research: A guide for researchers in education and the social sciences. Teachers College Press, New York.

[76] Wendy Shulver, Maggie Killington, and Maria Crotty. 2016. 'Massive potential'or 'safety risk'? Health worker views on telehealth in the care of older people and implications for successful normalization. BMC Medical Informatics and Decision Making 16, 1 (2016), 131.

[77] Jaspaljeet Singh, Christof Lutteroth, and Burkhard C Wünsche. 2010. Taxonomy of usability requirements for home telehealth systems. In Proceedings of the 11th International Conference of the NZ Chapter of the ACM Special Interest Group on Human-Computer Interaction. ACM, New York, 29-32.

[78] Anthony C Smith, Emma Thomas, Centaine L Snoswell, Helen Haydon, Ateev Mehrotra, Jane Clemensen, and Liam J Caffery. 2020. Telehealth for global emergencies: Implications for coronavirus disease 2019 (COVID-19). Fournal of Telemedicine and Telecare 26, 5 (2020), 309-313.

[79] Martha Strachan, Daniel F Gros, Kenneth J Ruggiero, Carl W Lejuez, and Ron Acierno. 2012. An integrated approach to delivering exposure-based treatment for symptoms of PTSD and depression in OIF/OEF veterans: Preliminary findings. Behavior Therapy 43, 3 (2012), 560-569.

[80] John Torous, Keris Jän Myrick, Natali Rauseo-Ricupero, and Joseph Firth. 2020. Digital mental health and COVID-19: using technology today to accelerate the curve on access and quality tomorrow. FMIR Mental Health 7, 3 (2020), e18848.

[81] Steven Walfish, Jeffrey E Barnett, and Jeffrey Zimmerman. 2017. Handbook of private practice: Keys to success for mental health practitioners. Oxford University Press, New York.

[82] Joseph B Walther. 2007. Selective self-presentation in computer-mediated communication: Hyperpersonal dimensions of technology, language, and cognition. Computers in Human Behavior 23, 5 (2007), 2538-2557. 
[83] Elizabeth Ann Wardle and Mary G Mayorga. 2016. Burnout among the counseling profession: A survey of future professional counselors. fournal on Educational Psychology 10, 1 (2016), 9-15.

[84] Theodore E Zorn, Andrew J Flanagin, and Mirit Devorah Shoham. 2011. Institutional and noninstitutional influences on information and communication technology adoption and use among nonprofit organizations. Human Communication Research 37, 1 (2011), 1-33.

Received October 2020; revised April 2021; revised July 2021; accepted July 2021 